02,13

\title{
Изготовление сверхпроводниковых туннельных структур с использованием электронно-лучевой литографии
}

\author{
(С) М.Ю. Фоминский, Л.В. Филиппенко, А.М. Чекушкин, В.П. Кошелец \\ Институт радиотехники и электроники им. В.А. Котельникова РАН, \\ Москва, Россия \\ E-mail: nanolith@yandex.ru
}

Поступила в Редакцию 9 апреля 2021 г.

В окончательной редакции 9 апреля 2021 г.

Принята к публикации 19 апреля 2021 г.

Разработана и оптимизирована технология изготовления субмикронных переходов $\mathrm{Nb}-\mathrm{AlN}-\mathrm{NbN}$ c использованием электронно-лучевой литографии. Были проведены исследования по подбору дозы экспонирования, времени проявления и параметров плазмохимического травления для получения максимального значения параметра качества туннельных переходов $R_{j} / R_{n}$. Использование негативного резиста та-N 2400 с меньшей чувствительностью и лучшим контрастом в сравнении с резистом UVN 2300-0.5 позволило улучшить воспроизводимость процесса изготовления структур. Это позволило изготовить туннельные переходы $\mathrm{Nb}-\mathrm{AlN}-\mathrm{NbN}$ с высокой плотностью тока и параметром качества $R_{j} / R_{n}>15$ субмикронных размеров (площадь от 2.0 до $0.2 \mu \mathrm{m}^{2}$ ). Экспериментально измерен разброс параметров туннельных структур субмикронных размеров по подложке, и воспроизводимость процесса изготовления структур от цикла к циклу.

Ключевые слова: электронно-лучевая литография, негативный электронный резист, плазмохимическое травление, магнетронное напыление, сверхпроводниковые туннельные структуры.

DOI: 10.21883/FTT.2021.09.51243.12H

\section{1. Введение}

Одним из наиболее успешно развиваемых направлений сверхпроводниковой электроники является разработка сверхчувствительных приемных устройств терагерцового диапазона. Важной задачей является развитие терагерцовых технологий и создания СИС-приемников с квантовой чувствительностью и источников $\mathrm{THz}$ излучения для использования в радиотелескопах космического и наземного базирования. Смесители на основе туннельных переходов сверхпроводник-изолятор-сверхпроводник (СИС) являются наилучшими входными устройствами на частотах от 0.1 до $1.2 \mathrm{THz}$, их шумовая температура ограничена только квантовым пределом. В настоящее время гетеродинные СИС-приемники используются в качестве штатных устройств на большинстве как наземных, так и космических радиотелескопов во всем мире [1,2]. Для реализации предельных параметров СИС-смесителей требуется создание и оптимизация воспроизводимой и надежной технологии изготовления наноструктур с толщиной туннельного барьера порядка $1 \mathrm{~nm} \mathrm{c}$ экстремально высокой плотностью тока и малыми токами утечки [3,4,5]. Для согласования с волноводными элементами смесителя площадь перехода с высокой плотностью тока должна составлять доли квадратного микрометра. Электронная литография является одним из наиболее перспективных методов для производства наноструктур в научно-исследовательских целях, поскольку позволяет оперативно изменять дизайн отдельных элементов и микросхемы в целом и добиться высокой воспроизводимости результатов в субмикронной области размеров туннельных переходов.

Для создания воспроизводимой и надежной технологии изготовления туннельных структур высокого качества, обладающих хорошей воспроизводимостью, с малым разбросом параметров по подложке, была разработана и отлажена технология изготовления туннельных структур субмикронных размеров $\mathrm{Nb}-\mathrm{AlN}-\mathrm{NbN}$ с помощью методов прямой электронно-лучевой литографии (ЭЛЛ) и последующим плазмохимическим травлением.

\section{2. Методика эксперимента}

Для исследования технологии изготовления переходов субмикронных размеров были изготовлены тестовые образцы, на которых в различных режимах электроннолучевого экспонирования, проявления и травления формировался массив из структур круглого сечения, как показано на рис. 1, разнесенных на расстояние более эффекта близости. СИС переход на подложке из кремния формировался путем травления трехслойной структуры $\mathrm{Nb}-\mathrm{AlN}-\mathrm{NbN}$ через маску резистивной пленки, сформированной при помощи электронной литографии. Трехслойная структура $\mathrm{Nb}-\mathrm{AlN}-\mathrm{NbN}$ напылялась с помощью установки Leybold L560UV, оснащенной водоохлаждаемым держателем подложек и двумя системами магнетронного распыления: на постоянном токе (DC) и высокой частоте (RF). Нижний ниобиевый 
Формирование трехслойной структуры в едином вакуумном цикле

\begin{tabular}{c|c|c|c}
\hline Материал & Назначение & Толщина, $\mathrm{nm}$ & Параметры напыления \\
\hline $\mathrm{Nb}$ & Нижний электрод & 200 & $\mathrm{DC}, 600 \mathrm{~W}, \mathrm{Ar}, 4 \mathrm{mTorr}, 1.8 \mathrm{~nm} / \mathrm{s}$ \\
\hline $\mathrm{Al}$ & Туннельный барьер & 6 & $\mathrm{DC}, 100 \mathrm{~W}, \mathrm{Ar}, 3 \mathrm{mTorr}, 0.13 \mathrm{~nm} / \mathrm{s}$ \\
\hline $\mathrm{AlN}$ & Туннельный барьер & $1.0-1.2$ & $\mathrm{RF}, 70 \mathrm{~W}, \mathrm{~N}_{2}, 0.03 \mathrm{mTorr}$ \\
\hline $\mathrm{NbN}$ & Верхний электрод & 80 & $\mathrm{DC}, 600 \mathrm{~W}, \mathrm{Ar}+\mathrm{N}_{2}, 4 \mathrm{mTorr}, 1.4 \mathrm{~nm} / \mathrm{s}$ \\
\hline
\end{tabular}

\begin{tabular}{c|l|c|c}
\hline Material & Description & Thickness, $\mathrm{nm}$ & Deposition parameters \\
\hline $\mathrm{Nb}$ & Base electrode & 200 & $\mathrm{DC}, 600 \mathrm{~W}, \mathrm{Ar}, 4 \mathrm{mTorr}, 1.8 \mathrm{~nm} / \mathrm{s}$ \\
\hline $\mathrm{Al}$ & Tunnel barrier & 6 & $\mathrm{DC}, 100 \mathrm{~W}, \mathrm{Ar}, 3 \mathrm{mTorr}, 0.13 \mathrm{~nm} / \mathrm{s}$ \\
\hline $\mathrm{AlN}$ & Tunnel barrier & $1.0-1.2$ & $\mathrm{RF}, 70 \mathrm{~W}, \mathrm{~N}_{2}, 0.03 \mathrm{mTorr}$ \\
\hline $\mathrm{NbN}$ & Counter electrode & 80 & DC, $600 \mathrm{~W}, A r+\mathrm{N}_{2}, 4 \mathrm{mTorr}, 1.4 \mathrm{~nm} / \mathrm{s}$
\end{tabular}

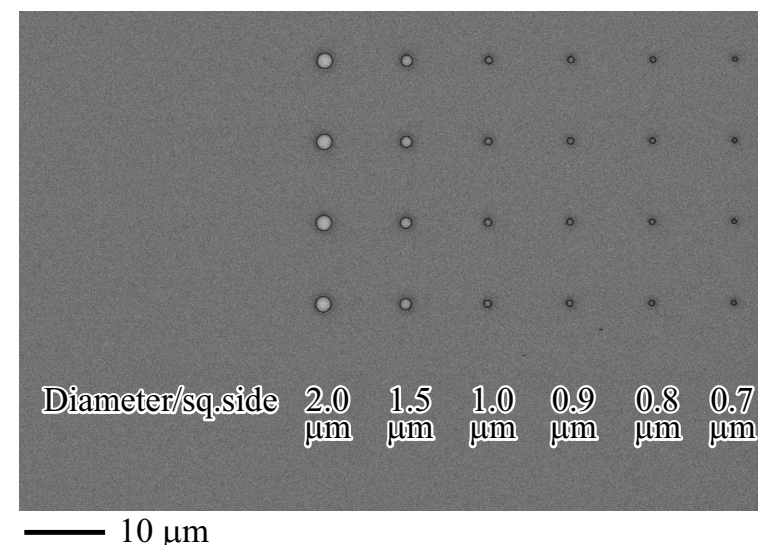

Рис. 1. Массив тестовых структур для отработки режимов изготовления переходов субмикронных размеров.

электрод и тонкий слой алюминия наносились методом магнетронного DC напыления в среде аргона. После напыления барьерного алюминия подложка помещалась над RF-магнетроном, на который крепилась мишень c алюминием, и инициировался плазменный разряд в среде азота [6]. После окончания процесса нитридизации на сформированный барьер осаждался слой верхнего электрода $\mathrm{NbN}$, который формировался методом магнетронного DC-напыления в среде аргона и азота. Cхема формирования трехслойной структуры представлена в таблице.

После формирования перехода при помощи плазмохимического травления проводилось анодирование, далее наносился слой изоляции $\mathrm{SiO}_{2}$. Заключающими этапами являются формирование верхнего электрода из $\mathrm{NbN}$ и контактных площадок Au. Каждый этап формирования туннельных переходов контролировался при помощи электронной микроскопии.
Для формирования геометрии переходов использовались различные типы негативных резистов. Негативный электронный резист UVN 2300-0.5 характеризуется высокой чувствительностью и используется как для фотолитографии (ГУФ, $248 \mathrm{~nm})$, так и для электронной литографии. Негативный электронный резист UVN 2300-0.5 наносился на предварительно сформированную трехслойную структуру $\mathrm{Nb}-\mathrm{AlN}-\mathrm{NbN}$. После нанесения резист подвергался термообработке $90^{\circ} \mathrm{C}$ в течение $10 \mathrm{~min}$. Толщина резистивной пленки составляла $0.38 \mu \mathrm{m}$. Экспонирование проводилось на установке электронной литографии Raith e_LiNE электронным пучком с энергией электронов $30 \mathrm{keV}$, доза варьировалась в зависимости от размера перехода в диапазоне от 8 до $20 \mu \mathrm{C} / \mathrm{cm}^{2}$. После экспонирования образцы нагревались до $110^{\circ} \mathrm{C}$ в течение $10 \mathrm{~min}$. Далее неэкспонированные участки резиста удалялись в $2.4 \%$ растворе тетраметиламмоний гидроксида пентагидрата. Негативный электронный резист UVN 2300-0.5 обладает низким контрастом, соответственно технологический процесс достаточно чувствителен к отклонениям, что сказывается на воспроизводимости результатов. Для резиста UVN 2300-0.5 подбирались подходящие дозы для переходов с различными заданными размерами (поправки учитывали отклонения по всей технологической карте):

доза $10 \mu \mathrm{C} / \mathrm{cm}^{2}$ оптимальна для структур с размерами 2.0 и $1.5 \mu \mathrm{m}$;

доза $15 \mu \mathrm{C} / \mathrm{cm}^{2}$ - для структур $0.7-1.0 \mu \mathrm{m}$;

доза $20 \mu \mathrm{C} / \mathrm{cm}^{2}$ - для структур $0.4-0.6 \mu \mathrm{m}$.

Таким образом были изготовлены и измерены переходы площадью до $0.15 \mu \mathrm{m}^{2}$, но для повышения воспроизводимости результатов и расширения „технологического окна“ были апробированы другие электронные резисты, в частности электронный резист ma-N 2400.

Негативный резист ma-N 2400 используется как для фотолитографии (ГУФ, $248 \mathrm{~nm})$, так и для электронной литографии, но чувствительность этого резиста 


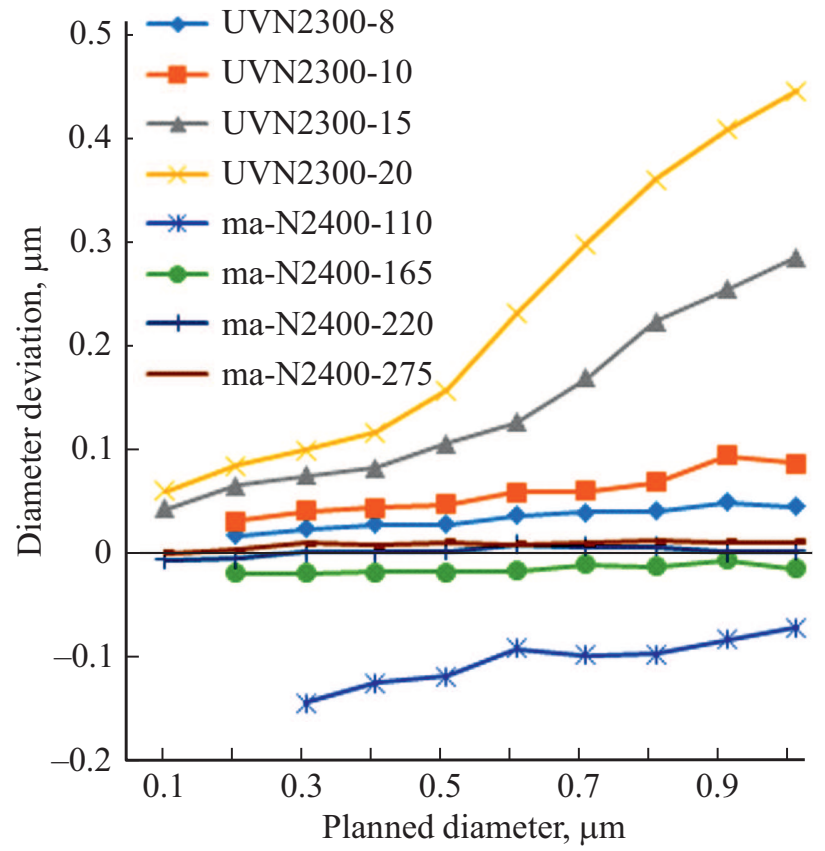

Рис. 2. Уход размеров переходов в процессе экспонирования и проявления (ТМАН $2.4 \%$, время $60 \mathrm{~s}$ ) для резистов та-N 2400 и UVN 2300-0.5. По горизонтальной оси проектируемый диаметр. По вертикальной оси разница диаметра структур, измеренных на электронном микроскопе, за вычетом заложенного в дизайне. Положительные значения соответствуют диаметру большему заложенного при изготовлении.

на порядок ниже чем у UVN 2300-0.5, поэтому для областей с малыми размерами разрешающая способность ma-N 2400 будет выше. Негативный электронный резист ma-N 2400 наносился на предварительно сформированную трехслойную структуру $\mathrm{Nb}-\mathrm{AlN}-\mathrm{NbN}$. После нанесения резист подвергался термообработке $90^{\circ} \mathrm{C}$ в течение $3 \mathrm{~min}$. Доза для ЭЛЛ варьировалась в диапазоне от 110 до $275 \mu \mathrm{C} / \mathrm{cm}^{2}$. Неэкспонированные участки резиста удалялись в растворе тетраметиламмоний гидроксида пентагидрата $2.4 \%$. Для повышения стойкости резистивной маски к травлению после проявления образцы нагревались до $100^{\circ} \mathrm{C}$ в течение $10 \mathrm{~min}$.

Использование негативного резиста ma-N 2400 (сплошная линия на рис. 2) с меньшей чувствительностью и лучшим контрастом в сравнении с UVN $2300-0.5$ позволило улучшить воспроизводимость процесса изготовления структур.

Негативный резист ma-N 2400 обладает чувствительностью на порядок ниже чем у UVN 2300-0.5 и лучшим контрастом. Как видно по данным измерений (сплошные кривые на рис. 2), для доз экспонирования 220 и $275 \mu \mathrm{C} / \mathrm{cm}^{2}$ уходы размеров постоянны (в отличие от резиста UVN 2300-0.5) и практически отсутствуют во всем диапазоне измерений от 1.0 до $0.1 \mu \mathrm{m}$. Для областей с малыми размерами (порядка $0.1 \mu \mathrm{m}$ ) разрешающая способность ma-N 2400 выше.

На рис. 3, 4, 5 приведены фотографии с электронного микроскопа последовательных этапов изготовления

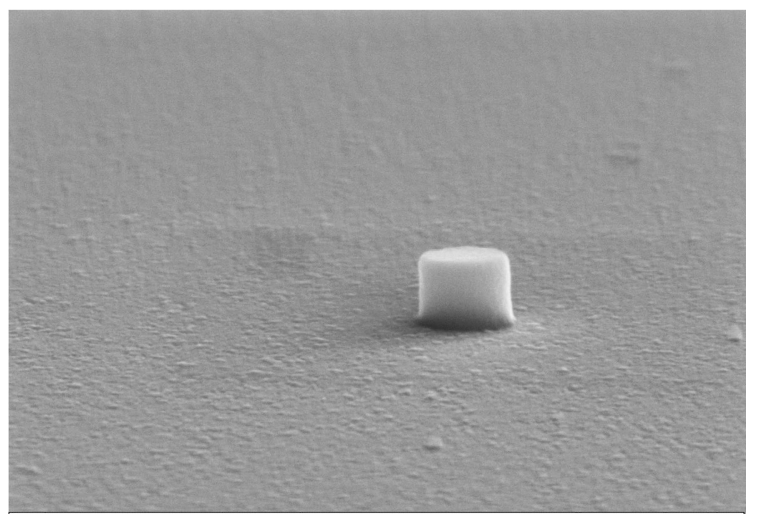

$$
-100 \mathrm{~nm}
$$

Рис. 3. Тестовый переход на основе резиста та-N 2400 диаметра $0.4 \mu \mathrm{m}$, экспонированный с дозой $220 \mu \mathrm{C} / \mathrm{cm}^{2}$; после проявления диаметр резиста для формирования тестового перехода составляет $0.37 \mu \mathrm{m}$.

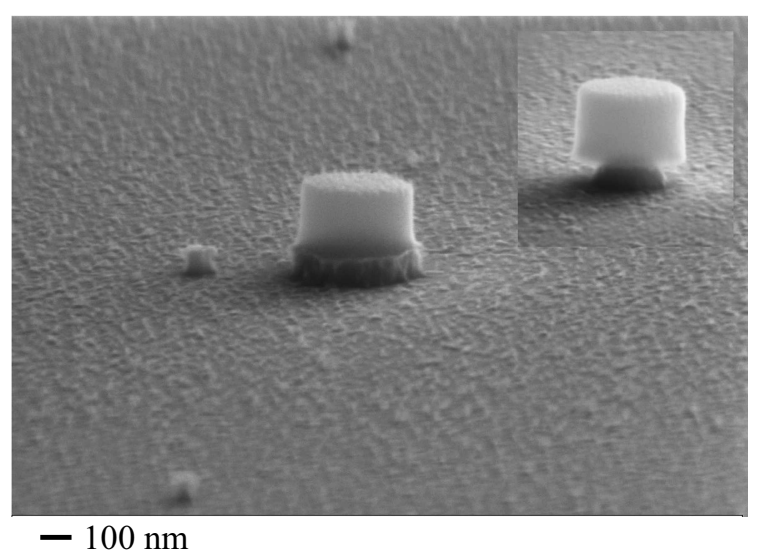

Рис. 4. Тестовый переход на основе резиста ma-N 2400 диаметра $0.4 \mu \mathrm{m}$, экспонированный с дозой $275 \mu \mathrm{C} / \mathrm{cm}^{2}$ после плазмохимического травления по маске резиста в атмосфеpe $\mathrm{CF}_{4}$. На вставке в правом верхнем углу образец после травления в атмосфере $\mathrm{CF}_{4}+\mathrm{O}_{2}$ с неоптимальными параметрами. Диаметр резиста после травления в обоих случаях составил $0.33 \mu \mathrm{m}$.

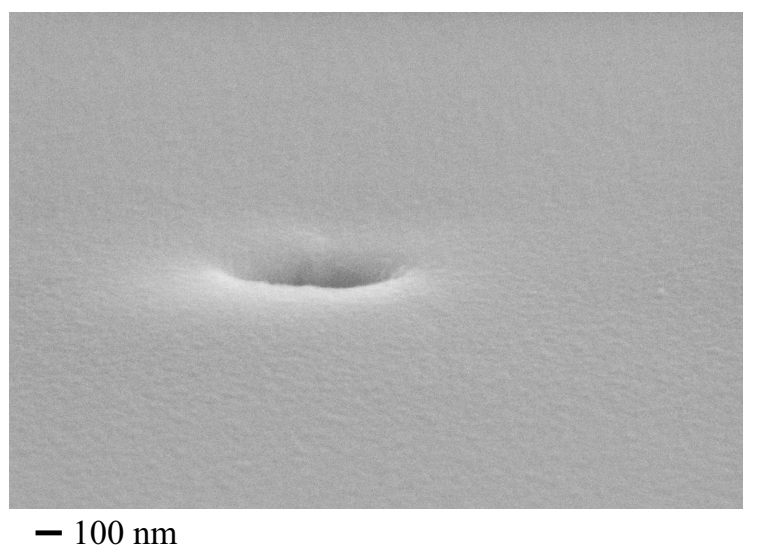

Рис. 5. Тестовый переход на основе резиста та-N 2400 диаметра $0.4 \mu \mathrm{m}$ после нанесения изоляции $\mathrm{SiO}_{2}$ и проведения „взрывной“ литографии. 


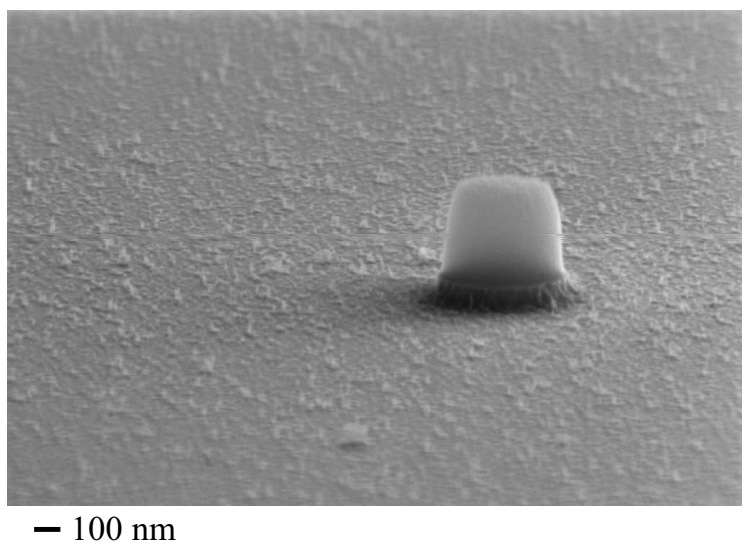

Рис. 6. Тестовый переход на основе резиста UVN 2300-0.5 диаметра $0.4 \mu \mathrm{m}$, экспонированный с дозой $20 \mu \mathrm{C} / \mathrm{cm}^{2}$; после плазмохимического травления по маске резиста в атмосфеpe $\mathrm{CF}_{4}$. Диаметр резистивной маски после травления $0.46 \mu \mathrm{m}$, диаметр трехслойной структуры $0.51 \mu \mathrm{m}$.

для структуры диаметром $0.4 \mu \mathrm{m}$ на основе резиста ma-N 2400.

Переходы формировались при помощи плазмохимического травления $\mathrm{NbN}$ по маске резиста (рис. 3). Этот процесс проходит в вакуумной камере установки плазмохимического травления Secon XPE II в смеси газов $\mathrm{O}_{2}$ и $\mathrm{CF}_{4}$.

С целью получения высокой воспроизводимости и малого разброса параметров было проведено исследование процесса травления и найдены оптимальные условия анизотропного травления пленки $\mathrm{NbN}$ с минимальным воспроизводимым подтравом (рис. 4). Контроль результата плазмохимического травления проводился с помощью электронного микроскопа.

После формирования перехода при помощи плазмохимического травления проводилось анодирование, в результате которого пленка нитрида ниобия, не закрытая резистом, превращалась в анодный окисел [7]. Далее наносился слой изоляции $\mathrm{SiO}_{2}$ (рис. 5).

На рис. 6 для сравнения приведена фотографии с электронного микроскопа для структуры такого же диаметра $0.4 \mu \mathrm{m}$, но на основе резиста UVN 2300-0.5. Виден существенно отличный от вертикального профиль резиста (недостаточный контраст UVN 2300-0.5), диаметр резистивной маски и трехслойной структуры существенно отличается от проектного размера.

Заключающими технологическими этапами являются формирование верхнего электрода из $\mathrm{NbN}$ и контактных площадок из золота с помощью фотолитографии с использованием фоторезиста AZ 5214.

\section{3. Результаты измерений}

Изготовлено несколько серий переходов $\mathrm{Nb}-\mathrm{AlN}-$ $\mathrm{NbN}$ с плотностью тока от 20 до $50 \mathrm{kA} / \mathrm{cm}^{2}$ субмикронных размеров. Измерения проводились при помощи автоматизированной системы измерения вольт-амперных

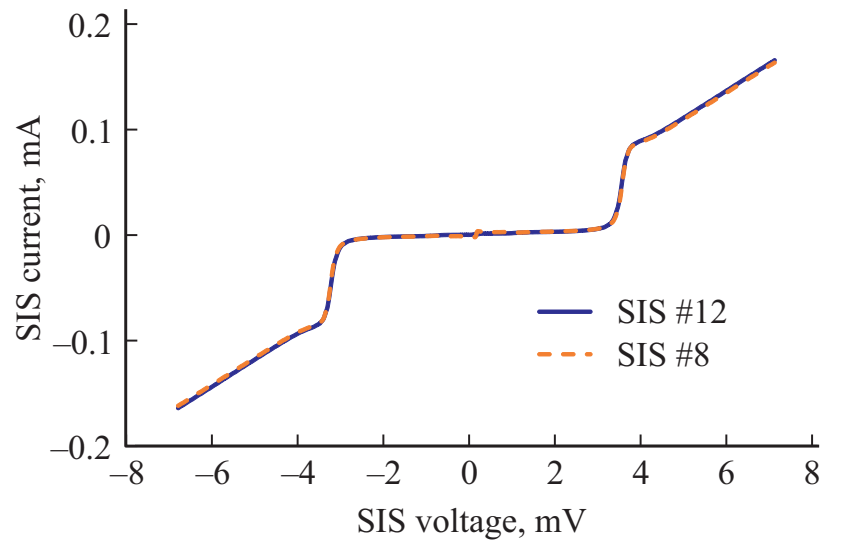

Рис. 7. ВАX переходов $\mathrm{Nb}-\mathrm{AlN}-\mathrm{NbN}$ одинакового размера, изготовленного с помощью ЭЛЛ, расположенных на разных частях одной подложки: SIS № 8 площадью $0.480 \mu \mathrm{m}^{2}$ с плотностью тока $15 \mathrm{kA} / \mathrm{cm}^{2}, R_{n}=40.98 \Omega, R_{j} / R_{n}=18.4$, $V_{g}=3.39 \mathrm{mV}$; SIS № 12 площадью $0.488 \mu \mathrm{m}^{2}$ с плотностью тока $15 \mathrm{kA} / \mathrm{cm}^{2}, R_{n}=40.34 \Omega, R_{j} / R_{n}=20.7, V_{g}=3.38 \mathrm{mV}$.

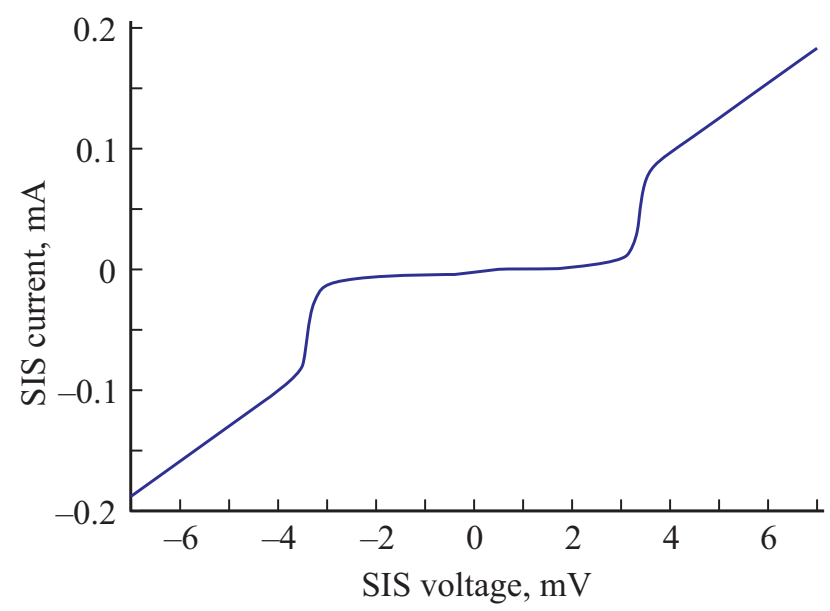

Рис. 8. $\mathrm{BAX}$ перехода $\mathrm{Nb}-\mathrm{AlN}-\mathrm{NbN}$ площадью $0.15 \mu \mathrm{m}^{2}$ с плотностью тока $47 \mathrm{kA} / \mathrm{cm}^{2}, R_{n}=34.53 \Omega, R_{j} / R_{n}=21.1$, $V_{g}=3.36 \mathrm{mV}$ изготовленного с помощью ЭЛЛ и плазмохимического травления.

характеристик и электрофизических параметров СИС переходов IRTECON. Для вольт-амперных характеристик переходов $\mathrm{Nb}-\mathrm{AlN}-\mathrm{NbN}$ одинакового размера, расположенных на разных частях подложки, были продемонстрированы сходные параметры, на рис. 7 приведены $\mathrm{BAX}$ переходов $\mathrm{Nb}-\mathrm{AlN}-\mathrm{NbN}$ одинакового размера, расположенных на разных частях одной подложки. Измерения проводились на переходах площадью до $0.15 \mu \mathrm{m}^{2}$, качество переходов при уменьшении размеров не изменялось (рис. 8).

\section{4. Заключение}

Была разработана и отлажена технология изготовления субмикронных переходов $\mathrm{Nb}-\mathrm{AlN}-\mathrm{NbN}$ с исполь- 
зованием электронно-лучевой литографии. Высококачественный сверхтонкий барьер AlN был сформирован в процессе нитридизации поверхности $\mathrm{Al}$ в плазменном RF-разряде в среде чистого $\mathrm{N}_{2}$. Были проведены исследования по подбору дозы экспонирования, времени проявления и параметров плазмохимического травления для получения максимально значения параметра качества туннельных переходов $R_{j} / R_{n}$. В дополнение к негативному резисту UVN 2300-0.5 были проведены исследования по подбору параметров для негативного резиста ma-N 2400, который обладает чувствительностью на порядок ниже чем у UVN 2300-0.5 и лучшим контрастом. Каждый этап формирования туннельных переходов контролировался при помощи электронной микроскопии. Это позволило изготовить туннельные переходы $\mathrm{Nb}-\mathrm{AlN}-\mathrm{NbN}$ с высокой плотностью тока и параметром качества $R_{j} / R_{n}>15$ субмикронных размеров (площадь от 2.0 до $0.2 \mu \mathrm{m}^{2}$ ). Экспериментально измерен разброс параметров туннельных структур субмикронных размеров по подложке, и воспроизводимость процесса изготовления структур от цикла к циклу.

\section{Финансирование работы}

Исследование выполнено при поддержке гранта РНФ 19-19-00618, туннельные структуры изготовлены в ИРЭ им. В.А. Котельникова РАН в рамках государственного задания с использованием УНУ 352529.

\section{Конфликт интересов}

Авторы заявляют, что у них нет конфликта интересов.

\section{Список литературы}

[1] Brian D. Jackson, Gert de Lange, Tony Zijlstra, Matthias Kroug, Jacob W. Kooi, Jeffrey A. Stern, Teun M. Klapwijk. IEEE Trans. Microw. Theory Techn. 54, 2, 547 (2006).

[2] A. Karpov, D. Miller, F. Rice, J.A. Stern, B. Bumble, H.G. LeDuc, J. Zmuidzinas. IEEE Trans. Appl. Supercond. 17, 2, 343 (2007).

[3] К.И. Рудаков, П.Н. Дмитриев, А.М. Барышев, А.В. Худченко, В.П. Кошелец. Изв. вузов. Радиофизика LIX, 08-09, 793 (2016).

[4] M.Yu. Torgashin, V.P. Koshelets, P.N. Dmitriev, A.B. Ermakov, L.V. Filippenko, P.A. Yagoubov. IEEE Trans. Appl. Supercond. 17, 2, 379 (2007).

[5] P.N. Dmitriev, I.L. Lapitskaya, L.V. Filippenko, A.B. Ermakov, S.V. Shitov, G.V. Prokopenko, S.A. Kovtonyuk, V.P. Koshelets. IEEE Trans. Appl. Supercond. 13, 2, 107 (2003).

[6] B. Bumble, H.G. LeDuc, J.A. Stern, K.G. Megerian. IEEE Trans. Appl. Supercond. 11, 1, 76 (2001).

[7] X. Meng, T. Van Duzer. IEEE Trans. Appl. Supercond. 13, 2, 91 (2003).

Редактор Т.Н. Василевская 